\title{
SISTEM PENUNJANG KEPUTUSAN PENERIMA PROGRAM KELUARGA HARAPAN DENGAN MENGGUNAKAN METODE TOPSIS
}

\author{
Okta Jaya Harmaja ${ }^{1)}$, Maria Septina Hutauruk ${ }^{2)}$, Maria Simarmata ${ }^{3)}$ \\ 1,2,3 Program Studi Sistem Informasi Fakultas Teknologi dan Ilmu Komputer, Universitas Prima Indonesia \\ oktajaya.h@gmail.com, mariaseptinahutauruk@gmail.com
}

\begin{abstract}
Currently poverty is still one of the problems faced by the people of Indonesia, based on data from the Central Statistics Agency (BPS), it is stated that the percentage of poor people in September 2019 was $9.22 \%$ or equivalent to 24.79 million people. One of the efforts that have been made by the Government to overcome the problem of poverty is the Family Hope Program (PKH). The program aims to break the chain or reduce the poverty index, increase human resources, and change behavior that is less supportive of improving the welfare of poor families. However, in its implementation there are still some problems that occur in the field, including the lack of a companion role, and some PKH recipients who are not on target, causing social suspicion. These problems can be overcome by using computer technology-based programs and still implementing transparent and accountable selection stages. In this study, the method used in the Decision Support System is the Technique for Order of Preference by Similarity to Ideal Solution (TOPSIS) method and the system is designed using the PHP programming language and MYSQL database. With this program, it is hoped that the user as the PKH implementation committee can make data easier, determine quickly and efficiently and on target for determining recipients of $P K H$ assistance.
\end{abstract}

Keywords: Decision Support System, TOPSIS, Family Hope Program, PHP, MySQL.

\section{PENDAHULUAN}

Kemiskinan dapat disebut keadaan sesesorang yang tidak dapat memenuhi kebutuhan seperti, makan, tempat tinggal, pakaian, rendahnya sebuah pendapatan, pendidikan dan keahlian kerja yang kurang memadai [1]. Kemiskinan merupakan salah suatu permasalahan yang hingga saat ini masih dihadapi oleh masyarakat Indonesia. Demi tercapainya kesejahteraan dan keadilan sosial bagi seluruh masyarakat Indonesia, tentunya Pemerintah selaku penyusun kebijakan telah melakukan berbagai upaya untuk menurunkan angka kemiskinan salah satunya dengan memberlakukan Program Keluarga Harapan (PKH).

PKH adalah program pemberian bantuan sosial bersyarat kepada Keluarga Miskin yang ditetapkan sebagai keluarga penerima manfaat PKH. Melalui PKH, Keluarga Miskin didorong untuk memiliki akses dan memanfaatkanpelayanan sosial dasar kesehatan, pendidikan, pangan dan gizi, perawatan, dan pendampingan, termasuk akses terhadap berbagai program perlindungan sosial lainnya yang merupakan program komplementer secara berkelanjutan. PKH diarahkan untuk menjadi episentrum dan center of excellence penanggulangan kemiskinan yang mensinergikan berbagai program perlindungan dan pemberdayaan sosial nasional.

Secara Nasional statistik pelaksanaan PKHdalam kurun waktu 4 tahun terakhir mengalami pengingkatan.Tahun 2016 sebanyak 5.981.528 Keluarga Miskin menerima bantuan dengan anggaran sebesar Rp. 7,6 Triliun. Jumlah penerima PKH tahun 2017 sebanyak 6.228.810 Keluarga Miskin dengan anggaran sebesar Rp. 11,3 Triliun.Jumlah penerima PKH tahun 2018 sebanyak 10.000.232 KPM dengan alokasi anggaran sebesar Rp. 17,5 Triliun. Pada tahun 2019 sebanyak 9.841.270 Keluarga Miskin menerima PKH dengan alokasi anggaran sebesar Rp. 32,7 Triliun.

Walaupun capaian target penurunan angka kemiskinan dan serapan penerimaan bantuan PKH sudah berjalan baik, namum masih terdapat beberapa permasalahaan yang terjadi dilapangan Pada pelaksanaannya diantaranya kurangnya peran pendamping, dan penerima PKH ada yang tidak tepat sasaran, sehingga menimbulkan kecurigaan sosial. Pemerataan dan efektifitas penyaluran bantuan untuk PKH sangat diperlukan agar program tersebut tepat sasaran.

Seiring dengan perkembangan zaman saat ini, penerapan teknologi sudah banyak dimanfaatkan dalam berbagai bidang kehidupan 
masyarakat [2]-[6], [7]-[16], [17]-[21]. Salah satu teknologi yang banyak dimanfaatkan untuk kehidupan masyarakat adalah teknik pengambilan keputusan dengan menggunakan bantuan sistem pendukung keputusan [22], [23], [24]-[28]. Dalam penelitian ini, akan dirancang sebuah sistem pendukung keputusan untuk seleksi penerima program PKH. Sistem seleksi penerima PKH ini sudah pernah dikembangkan oleh beberapa peneliti lain dengan menggunakan metode Analytycal Hierarchy Process (AHP) [29], Simple Addative Weighting (SAW) [30], [31], dan metode TOPSIS [32]. Masing-masing dari beberapa peneliti tersebut menggunakan kriteria dan platform yang berbeda-beda untuk program seleksi penerima PKH.

Pada penelitian ini terdapat 6 kriteria yang digunakan, kriteria ini berdasarkan data dan syarat penerima PKH yang telah diatur didalam kebijakan Dinas Sosial. Dengan harapan akan memberikan hasil yang lebih akurat dan tepat sasaran. Kriteria yang digunakan adalah Penyandang Disabilitas (C1), Lansia (C2), Jumlah Anak untuk Tanggungan Pendidikan (C3), Besar Pendapatan Bulanan (C4), Luas Bangunan Rumah (C5), Ibu Hamil (C6).

Penelitian ini bertujuan untuk menerapkan metode Technique for Order of Preference by Similarity to Ideal Solution (TOPSIS) yang akan digunakan pada Sistem Pendukung Keputusan PKH. Sistem dirancang dengan menggunakan bahasa pemograman PHP serta database MySQL. Pemilihan metode TOPSIS diharapkan dapat mendukung nilai keakuratan kriteria dengan penentuan nilai ideal dan solusi terbarik bagi calon penerima PKH. Dengan menggunakan Sistem Pendukung Keptusan dan penentuan kriteria yang sesuai dengan kebijakan sertametode yang tepat diharapkan pelaksanaan PKH lebih efisien dan tepat sasaran.Dari sisi operasional pelaksanaan, diharapkan user yang bertindak sebagai panitia pelaksana program PKH (Dinas Sosial Kota Medan) dapat dipermudah dalam melakukan pemrosesan dan pendataan dari calon penerima program PKH dengan bantuan sistem yang dirancang pada penelitian ini.

\section{METODE PENELITIAN}

Pada penelitian ini studi kasus wilayah serapan PKH adalah wilayah Kota Medan. Secara statistik jumlah penerima PKH di Kota Medan adalah 52.461 Keluarga Miskinatau
$11.72 \%$ dari wilayah lain yang terdapat di Provinsi Sumatera Utara dengan jumlah bantuan 14.015.241.350 Miliar [33], [34].

\section{HASIL DAN PEMBAHASAN}

\subsection{Technique For Other Reference by Similarity to Ideal Solution(TOPSIS)}

Metode TOPSIS merupakan salah satu metode yangdapat digunakan untuk menentukan pengambilan keputusan multikriteria atau alternatif pilihan yang merupakan alternatif yang mempunyai jarak terkecil dari solusi ideal positif dan jarak terbesar dari solusi ideal negatif dari sudut pandang geometris dengan menggunakan jarak Euclidean [26].

Adapun tahapan yang dapat dilakukan untuk penyelesaian permasalahan dengan menggunakan metode TOPSIS adalah sebagai berikut:

1. Penentuan kriteria yang akan digunakan dalam perhitungan TOPSIS sebagai dasar penilaian untuk alternatif.

Pada penelitian ini kriteria yang digunakan adalah sebagai berikut.

Tabel 1. Kriteria Penerima Program Keluarga Harapan

\begin{tabular}{|c|c|c|c|}
\hline No & Kode & Nama Kriteria & Nilai \\
\hline 1 & $\mathrm{C} 1$ & $\begin{array}{l}\text { Penyandang } \\
\text { Disabilitas }\end{array}$ & $\begin{array}{c}0-\mathrm{n} \\
(\text { Orang) }\end{array}$ \\
\hline 2 & $\mathrm{C} 2$ & Lansia & $\begin{array}{c}0-\mathrm{n} \\
\text { (Orang) }\end{array}$ \\
\hline 3 & $\mathrm{C} 3$ & Jumlah Anak & $\begin{array}{c}1-\mathrm{n} \\
(\text { Anak) }\end{array}$ \\
\hline 4 & $\mathrm{C} 4$ & $\begin{array}{l}\text { Besar } \\
\text { Pendapatan } \\
\text { Bulanan }\end{array}$ & $\begin{array}{l}100 \text { ribu - } \\
1.5 \text { juta }\end{array}$ \\
\hline 5 & $\mathrm{C} 5$ & $\begin{array}{l}\text { Luas Bangunan } \\
\text { Rumah }\end{array}$ & $\begin{array}{c}8-30\left(\mathrm{~m}^{2}\right) \\
\text { / orang }\end{array}$ \\
\hline 6 & C6 & Ibu Hamil & $\begin{array}{c}0-8 \\
\text { (Bulan) }\end{array}$ \\
\hline
\end{tabular}

Nilai $\mathrm{n}$ merupakan jumlah maximum yang dapat diisi pada kriteria. Nilai 0 menandakan objek yang akan diukur nantinya tidak memenuhi atau tidak memiliki keteria tersebut. Hal ini dilakukan dengan mempertimbangkan bahwa setiap calon penerima program PKH belum tentu memenuhi keseluruhan keriteria yang telah ditentukan pada Tabel 1 .

2. Penentuan alternatif yang berupa dapat berupa orang/objek yang akan dinilai dapat perhitungan TOPSIS.

3. Menggambarkan alternatif (m) dan kriteria(n) kedalam sebuah matriks, 
dimana $X_{\mathrm{ij}}$ adalah pengukuran pilihan dari alternatif ke-i dan kriteria ke-j. Matriks ini dapat dilihat pada persamaan (1).

$\mathrm{D}=\left[\begin{array}{ccc}X_{11} & X_{12} \ldots & X_{13} \\ X_{21} & X_{22} \ldots & X_{23} \\ X_{i 1} & X_{i 2} \ldots & X_{i 3}\end{array}\right]$

4. Membuat matriks $\mathrm{R}$ yaitu matriks keputusan ternormalisasi. Setiap normalisasi darinilair ${ }_{i j}$ dapat dilakukan dengan perhitungan menggunakan persamaan (2).

$\mathrm{r}_{\mathrm{ij}}=\frac{X_{i j}}{\sqrt{\sum_{i=1}^{m} x_{i j}}}$

5. Membuat pembobotan pada matriks yang telah dinormalisasi Setelah dinormalisasi, setiap kolom pada matriks $\mathrm{R}$ dikalikan dengan bobot-bobot $\left(\mathrm{w}_{\mathrm{j}}\right)$ untuk menghasilkan matriks pada persamaan (3).

$$
\mathrm{D}=\left[\begin{array}{ccc}
W_{1} r_{11} & W_{1} r_{12} & W_{n} r_{n} \\
W_{2} r_{21} & \ldots & \ldots \\
W_{j} r_{m 1} & W_{j} r_{m 2} & W_{j} r_{m m}
\end{array}\right]
$$

6. Menentukan nilai solusi ideal positif dan solusi ideal negatif. Solusi ideal dinotasikan $\mathrm{A}^{+}$, sedangkan solusi ideal negatif dinotasikan $\mathrm{A}^{-}$. Persamaan untuk menentukan solusi ideal dapat diperoleh berdasarkan rating bobot ternormalisasi $\left(Y_{i j}\right)$ pada persampaan (4).

$$
y_{i j}=w_{i} r_{i j}
$$

dengan $i=1,2,3, . ., m$ dan $j=1,2,3, \ldots, n$

7. Menentukan matriks solusi ideal dan matriks solusi ideal negatif. Solusi ideal positif $\left(\mathrm{A}^{+}\right)$dihitung berdasarkan persamaan (5).

$A^{+}=\left(y 1^{+}, y 2^{+}, y 3^{+}, \ldots, y n^{+}\right)$

Solusi ideal negatif $\left(\mathrm{A}^{-}\right)$dihitung berdasarkan persamaan (6).

$A^{-}=\left(y 1^{-}, y 2^{-}, y 3^{-}, \ldots, y n^{-}\right)$

8. Menentukan jarak antara nilai setiap alternatif dengan matriks solusi ideal positif dan matrik ideal negatif.

Jarak antara alternatif $A_{i}$ dengan solusi ideal positif dirumuskan sebagai:

$$
\mathrm{D}_{\mathrm{i}}^{+}=\sqrt{\sum_{j=1}^{n}\left(y_{i j}-y_{i}^{+}\right)^{2}}, \mathrm{i}=1,2,3, \ldots \mathrm{m}
$$

Jarak antara alternatif $A_{i}$ dengan solusi ideal negatif dirumuskan sebagai:

$$
\mathrm{D}_{\mathrm{i}}^{+}=\sqrt{\sum_{j=1}^{n}\left(y_{i j}-y_{i}^{-}\right)^{2}}, \mathrm{i}=1,2,3, \ldots \mathrm{m}
$$

9. Menentukan nilai preferensi untuk setiap alternatif. Kedekatan untuk setiap alternatif terhadap solusi ideal dihitung berdasarkan rumus:

$\mathrm{V}=\frac{D i^{-}}{D i^{-}+D i^{+}}, \mathrm{i}=1,2,3, \ldots \mathrm{m}$

Alternatif terbaik yaitu alternatif yang memiliki jarak terpendek dari solusi ideal dan berjarak terjauh dari solusi ideal negatif.

Adapaun secara umum tahapan penelitian dapat dilihat pada Gambar 1.

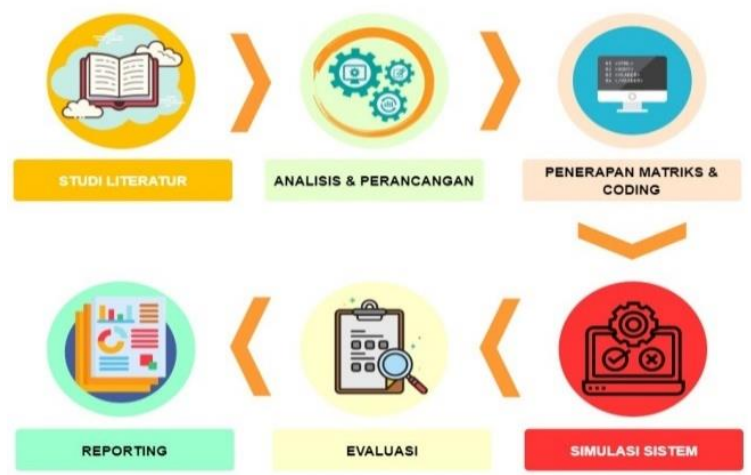

Gambar 1. Diagram Blok Tahapan Penelitian

Perancangan sistem pengambilan keputusanseleksi calon penerima bantuan Program Harapan Keluarga (PKH) di Dinas Sosial Kota Medan melibatkan data yang berkaitan dan prosedur yang telah ditetapkan sesuai dengan kebijakan yang berlaku. Model awal sistem dibangun dengan menggambarkan use case diagram agar dapat mengetahui aktivitas yang akan dilakukan didalam sistem dan akan sesuai dengan kebutuhan dari pelaksanaan program PKH. Use case diagram dari program SPK PKH dapat dilihat pada Gambar 2.

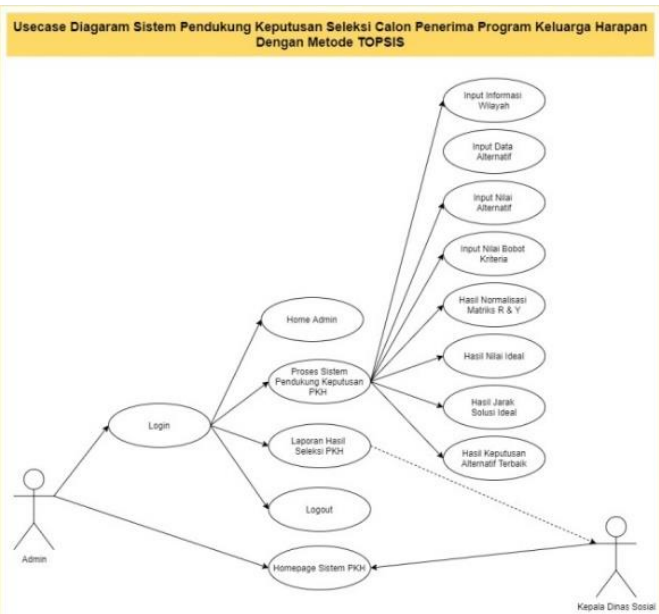

Gambar 2. Use Case DiagramSPK PKH 
Selanjutnya perancangan alur sistem dari program SPK PHK yang merupakan gambaran dari proses awal sistem berjalan hingga sistem menghasilkan sebuah ouput berupada data, yang digunakan sebagai acuan data Kepala Dinas dalam menentukan penerima bantuan PKH. Alur sistem secara keseluruhan dapat dilihat pada Gambar 3.

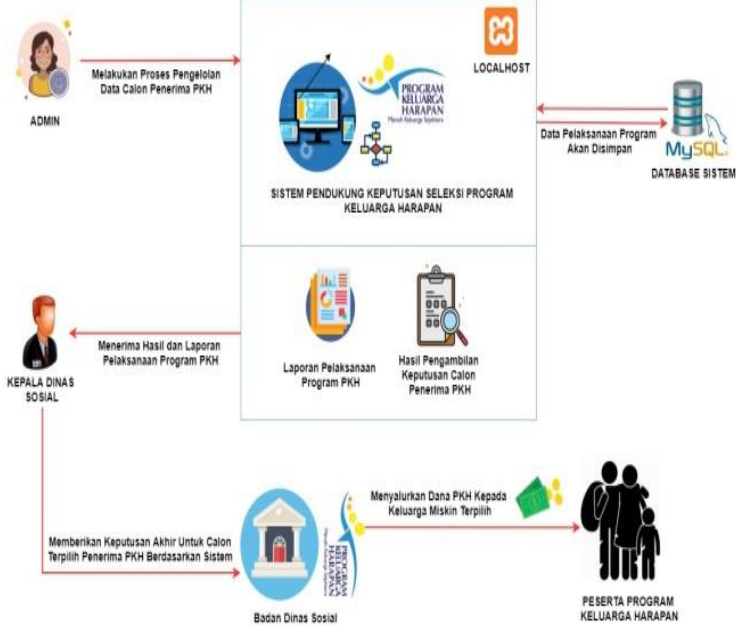

Gambar 3. Diagram Block Proses Sistem Informasi Pendukung Keputusan Penerima PKH

Gambar 3 menjelaskan bahwa calon penerima PKH sebelumnya telah didata oleh data kelurahan setempat dan dari data tersebut akan digunakan oleh panita penyelenggara program PKH untuk melakukan proses seleksi penerima PKH. Panitia penyelenggara yang menggunakan sistem dan bertindak sebagai admin akan melakukan penginputan data dari calon penerima dan mengisi nilai-nilai berdasarkan kriteria dan data yang telah diperoleh di sistem SPK PKH. Dari proses ini akan menghasilkan suatu keputusan terkait hasil seleksi dari calon penerima PKH. Hasil tersebut akan dirubah kedalam bentuk laporan untuk segera diberikan ke pihak top level management yaitu Kepala Dinas Sosial untuk memberikan keputusan lanjutan dari hasil yang telah diperoleh dengan menggunakan program SPK PKH. Pada penelitian ini sistem yang dirancang masih menggunakan localhost sebagai base server dan database MySQL. Namun untuk kedepannya data yang ada di localhost dapat di migrasikan ke sistem yang dengan web-hosting dan berbaisonline untuk memudahkan proses rekapitulasi, komunikasi dan integrasi dengan sistem lainnya.

Adapun hasil uji simulasi SPK PKH dapat dilihat pada gambar dibawah ini.
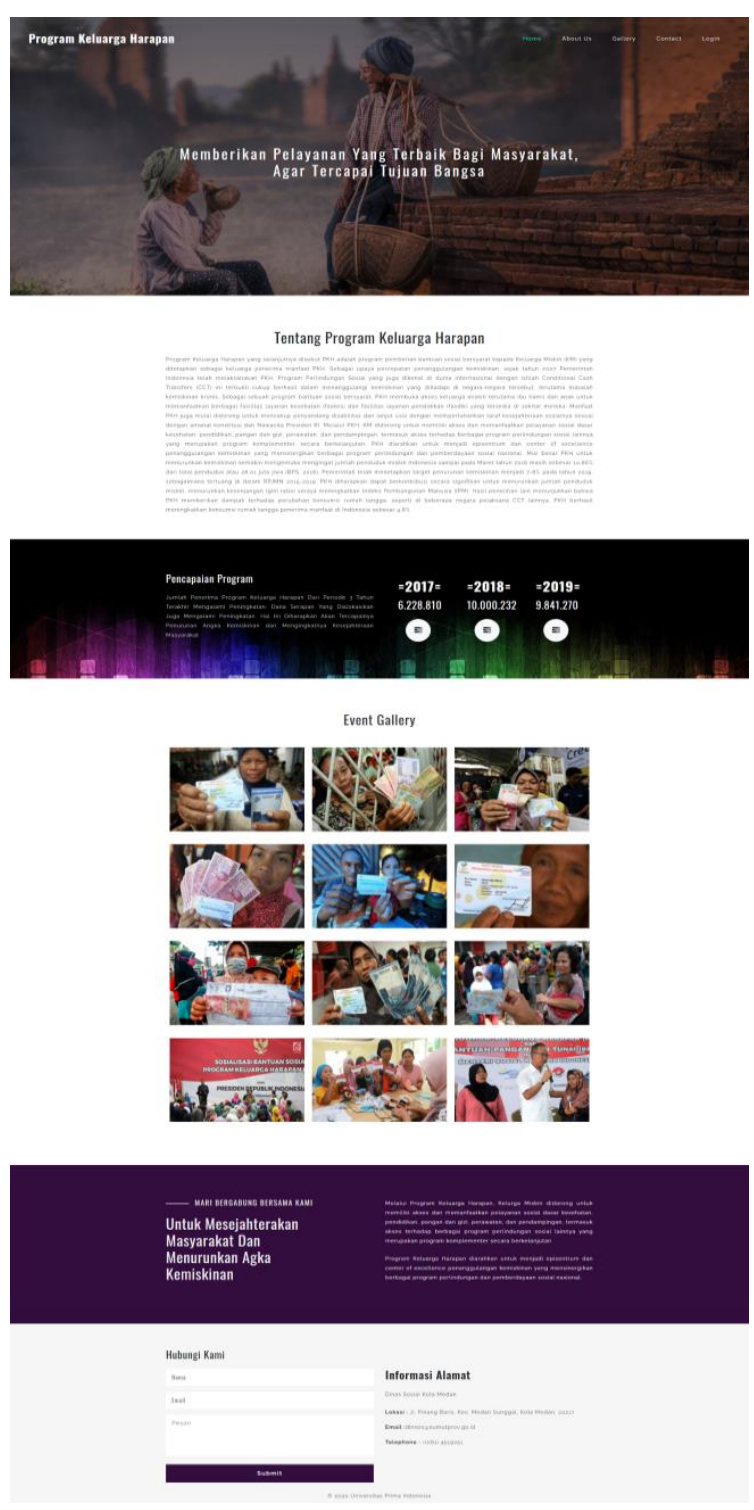

Gambar 4. Front End Dari SPK PKH

Pada gambar 10, merupakan front-end dari sistem SPK PKH yang diperuntukkan untuk user secara umum. Pada halaman tersebut terdapat beberapa informasi seperti informasi terkait $\mathrm{PKH}$, pencapaian target serapan dana dan bantuan $\mathrm{PKH}$, eventgallery dari aktivitas PKH, dan informasi kontak Dinas Sosial Provinsi Kota Medan.

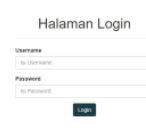

Gambar 5. Halaman Login Admin 
Gambar 5 merupakan tampilan login admin dari SPK PKH yang dirancang. Untuk mendapatkan hak akses username dan password untuk userbaru akan dibuat langsung didalam database MySQL dengan melakukan queryinsert.

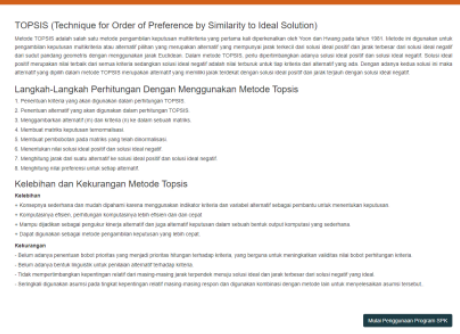

Gambar 6. Back End Dari SPK PKH

Gambar 6 merupakan tampilan back-end dari sistem pada saat login admintelah berhasil dilakukan. Dalam halaman ini terdapat beberapa informasi mengenai metode yang digunakan dalam SPK PKH. Menu yang terdapat pada halaman ini adalah Home, Laporan untuk melihat hasil pengolahan dari data-data calon PKH dengan SPK metode Topsis dan menu logout.

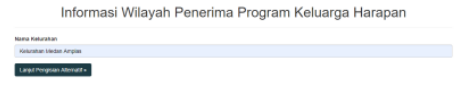

Gambar 7. HalamanUntuk Mengisi Informasi Wilayah Kelurahan

Gambar 7 merupakan tampilan untuk mengisi wilayah kelurahan untuk memperkecil scope penilaian yang akan dilakukan pada saat proses $\mathrm{PKH}$, maksud dari halaman ini bertujuan untuk menghasilkan pemerataan dan efektifitas dalam proses $\mathrm{PKH}$.

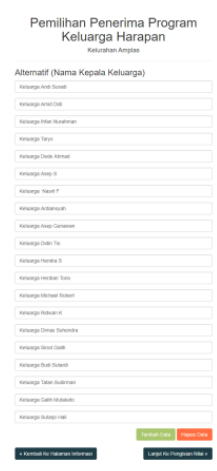

Gambar 8. Halaman Untuk Mengisi Alternatif
Gambar 8 merupakan tampilan untuk halaman pengisian alternatif dimana objek yang dituju adalah nama kepala keluarga dari calon penerima PKH. Nama tersebut dapat diperoleh dari pendaataan dari setiap kelurahan di kota Medan dilakukan oleh dinas sosial ataupun badan statistik, sehingga user dapat langsung melakukan proses pengisian untuk pengolahan PKH.

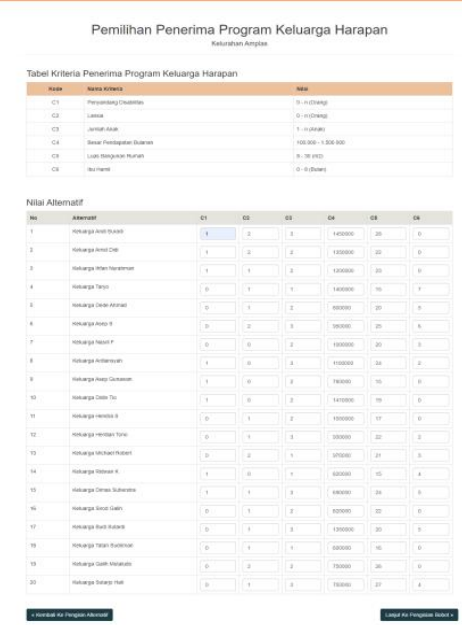

Gambar 9. Halaman Untuk Mengisi Nilai Alternatif

Gambar 9 merupakan tampilan untuk halaman pengisian nilai dari alternatif yang telah di-input sebelumnya. Nilai dari alternative disesuaikan dengan kondisi keluarga calon penerima $\mathrm{PKH}$ dan kriteria serta parameter yang telah dijelaskan pada Tabel 1. Pengisian nilai alternatif pada saat implementasi harus benarbenar diisi dengan kondisi realdari keadaan kepala keluarga calon penerima PKH agar hasil yang diperoleh nantinya tepat sasaran. Pada halaman ini juga dilengkapi dengan fitur minimum value dan maximum value sehingga apabila data yang di-input melebihi atau kurang dari batas parameter yang telah ditentukan maka sistem akan memberikan notifikasi kesalahan input, sehingga user akan mengisi kembali data dengan benar sesuai dengan parameter yang telah ditentukan.

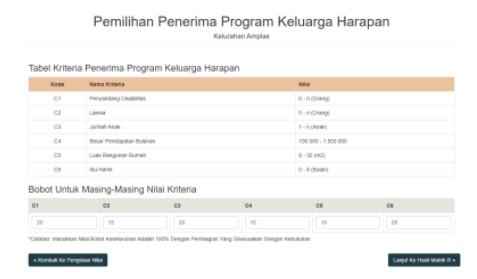


Gambar 10. Halaman Untuk Mengisi Nilai Bobot Untuk Masing-Masing Kriteria

Gambar 10 merupakan tampilan untuk halaman pengisian nilai bobot dari dari krireria yang diuganakan. Pembobotan kriteria ini digunakan agar hasil perhitungan lebih sesuai dengan yang telah di-input sebelumnya. Total nilai bobot dari keseluruhan kriteria adalah $100 \%$ dengan pembagian yang disesuaikan dengan kebutuhan. Dari simulasi yang telah dilakukan pada penelitian ini, pembagian nilai bobot kriteria yang digunakan adalah $\mathrm{C} 1=20$, $\mathrm{C} 2=15, \mathrm{C} 3=20, \mathrm{C} 4=15, \mathrm{C} 5=10, \mathrm{C} 6=20$.

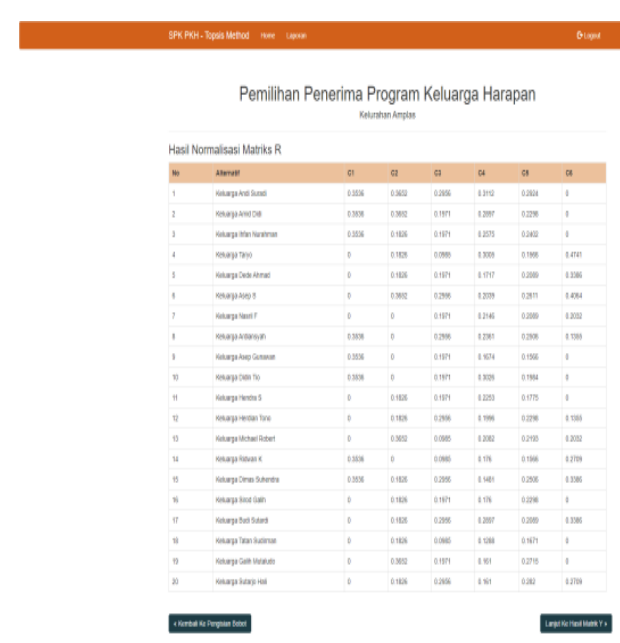

Gambar 11. Halaman Untuk Hasil Normalisasi Matriks R

Setelah melakukan pengisian nilai bobot kriteria maka selanjutnya merupakan hasil pengolahaan data dengan normalisasi matriks $\mathrm{R}$ berdasarkan metode TOPSIS seperti yang terlihat pada Gambar 11.

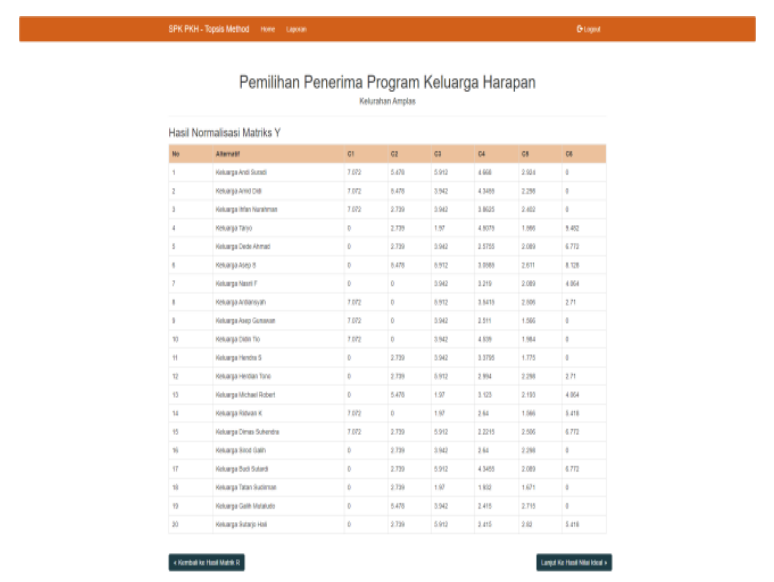

Gambar 12. Halaman Untuk Hasil Normalisasi Matriks Y

Gambar 12 merupakan tampilan untuk hasil pengolahan data untuk normalisasi matriks Y.
Hasil tersebut juga diperoleh dari persamaan yang telah disebutkan sebelumnya.

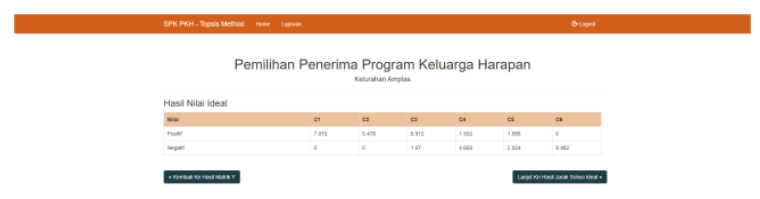

Gambar 13. Halaman Untuk Hasil Nilai Ideal

Hasil nilai ideal merupakan hasil untuk menentukan nilai negatif dan positif dari data nilai kriteria yang telah diproses pada tahapan sebelumnya. Hasil ini diperoleh dengan menggunakan persamaan (5) dan (6). Hasil tersebut akan digunakan untuk proses penentuan jarak solusi ideal dari setiap alternatif seperti yang terlihat pada Gambar 14.

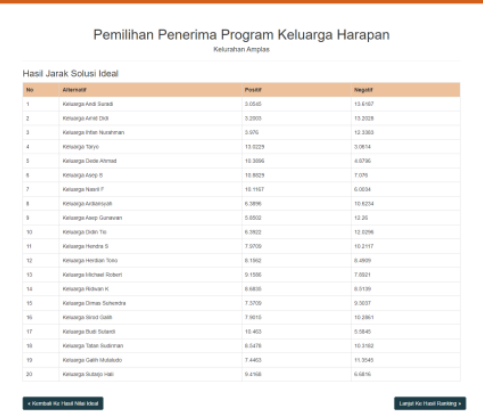

Gambar 14. Halaman Untuk Hasil Jarak Solusi Ideal

Jarak solusi ideal diperoleh dengan menggunakan persamaan (7) untuk solusi ideal positif dan persamaan (8) untuk solusi ideal negatif. Dengan tahapan yang telah dilakukan maka proses penentuan nilai preferensi untuk setiap alternatif untuk mencari alternatif terbaik. Hasil dari pengolahan dapat dilihat pada Gambar 15 .

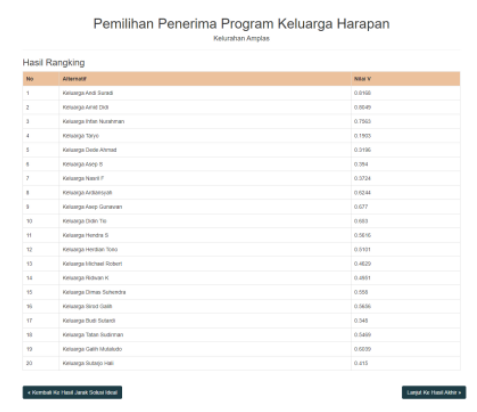

Gambar 15. Halaman Untuk Nilai Ranking 
Hasil nilai preferensi yang diperoleh akan dilakukan perangkingan sesuai dengan alternatif terbaik seperti yang terlihat Gambar 16.

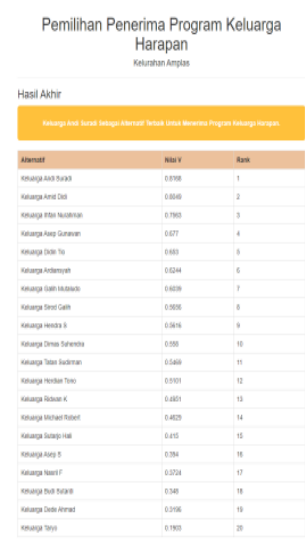

Gambar 16. Halaman Hasil Keputusan Alternatif Terbaik

Pada halaman hasil keputusan alternatif terbaik, alternatif untuk calon penerima $\mathrm{PKH}$ akan diurutkan berdasarkan rangking dari nilai preferensi yang telah diperoleh pada sebelumnya. Pada simulasi yang dilakukan alternatif terbaik untuk mendapatkan bantuan PKH di wilayah Kelurahan Amplas adalah keluarga Andi Suradi dengan nilai 0.8168. Berdasarkan simulasi dan dilihat dari nilai alternatif yang digunakan sebelumnya keluarga Andri Suradi secara keseluruhan memenuhi aspek dari setiap kriteria yang ada.

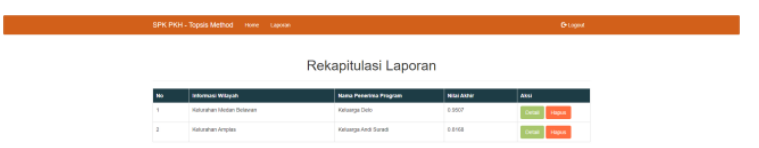

\section{Gambar 17. Halaman Rekapitulasi Laporan Dari SPK PKH}

Gambar 17 merupakan tampilan dari halaman rekapitulasi laporan untuk setiap proses pengolahan data dari calon penerima PKH. Adapaun detail dari laporan dapat dilihat seperti pada Gambar 18.

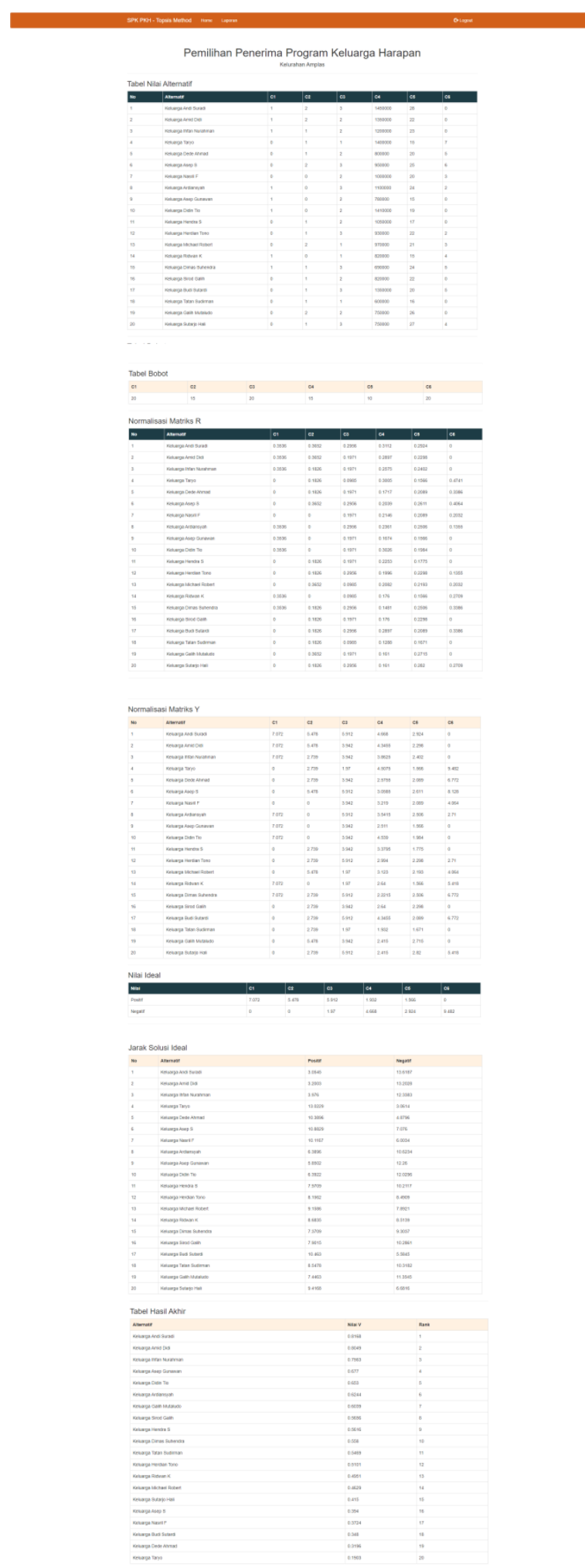

Gambar 18. Detail Rekapitulasi Laporan Dari SPK PKH

Hasil detail rekapitulasi proses seleksi calon penerima $\mathrm{PKH}$ dengan menggunakan SPK ini akan digunakan untuk proses laporan ke pihak Top Level ManagementDinas Sosial Kota Medan. 


\section{KESIMPULAN}

Pada penelitian ini Sistem Pendukung Keputusan seleksi calon penerima Program Keluarga Harapan dengan menggunakan metode TOPSIS telah berhasil dibangun dan disimulasikan. Sistem yang dihasilkan telah memenuhi tujuan awal dari penelitian yaitu untuk membuat suatu sistem yang efektif dalam pendataan dan pemrosesanpelaksanaan program PKH. Sistem juga dapat mempercepat proses seleksi calon penerima PKH dengan hasil yang transaparan dan dapat dipertanggungjawabkan. Hasil akhir dari sistem ini merupakan laporan pelaksanaan program PKH yang dapat digunakan oleh Top Level Managementdan sebagai bahan untuk audit nantinya.

\section{REFERENSI}

[1] G. A. Aziz, E. Rochaida, and Warsilan, "Faktor Faktor Yang Mempengaruhi Kemiskinan Di Kabupaten Kutai Kartanegara," J. Ekon. Keuang. dan Manaj., vol. 12, no. 1, pp. 29-48, 2016.

[2] P. Adi, D. Prasetya, A. Setiawan, N. Nachrowie, and R. Arifuddin, "Design Of Tsunami Detector Based Sort Message Service Using Arduino and SIM900A to GSM/GPRS Module," Proc. Proc. 2nd Int. Conf. Adv. Sci. Innov. ICASI 2019, 18 July, Banda Aceh, Indones., 2019.

[3] P. D. P. Adi and A. Kitagawa, "Quality of Service and power consumption optimization on the IEEE 802.15.4 pulse sensor node based on Internet of Things," Int. J. Adv. Comput. Sci. Appl., 2019.

[4] P. D. P. Adi and A. Kitagawa, "Performance evaluation of E32 long range radio frequency $915 \mathrm{MHz}$ based on internet of things and micro sensors data," Int. J. Adv. Comput. Sci. Appl., vol. 10, no. 11, pp. 38-49, 2019.

[5] M. Niswar et al., "Performance evaluation of ZigBee-based wireless sensor network for monitoring patients' pulse status," in Proceedings - 2013 International Conference on Information Technology and Electrical Engineering: "Intelligent and Green Technologies for Sustainable Development", ICITEE 2013, 2013.

[6] P. D. P. Adi and A. Kitagawa, "ZigBee Radio Frequency (RF) performance on Raspberry Pi 3 for Internet of Things
(IoT) based blood pressure sensors monitoring," Int. J. Adv. Comput. Sci. Appl., 2019.

[7] W. Purba, S. Aisyah, and S. P. Tamba, "Perancangan Sistem Pakar Diagnosa Penyakit Mata Katarak Menggunakan Konsep Metode Runut Mundur," JUSIKOM PRIMA (Junal Sist. Inf. Ilmu Komput. Prima), vol. 1, no. 1, 2017.

[8] G. J. Yanris, "Analisis Dan Implementasi Data Mining Dalam Menganalisa Kendala Akademik Yang Sering Dikeluhkan Mahasiswa AMIK Labuhanbatu (Studi Kasus: Amik Labuhanbatu)," Informatika, vol. 4, no. 1, pp. 15-24, 2016.

[9] J. Simatupang and S. Sianturi, "PERANCANGAN SISTEM INFORMASI PEMESANAN TIKET BUS PADA PO. HANDOYO BERBASIS ONLINE," J. Intra Tech, vol. 3, no. 2, pp. 11-25, 2019.

[10] V. Sihombing and G. J. Yanris, "PENERAPAN APLIKASI DALAM MENGOLAH ASET DESA (STUDI KASUS: KEPENGHULUAN SRI KAYANGAN)," J. Mantik Penusa, vol. 4, no. 1, pp. 12-15, 2020.

[11] V. Sihombing, "Aplikasi Simade (Sistem Informasi Manajemen Desa) Dalam Meningkatkan Pelayanan Administrasi di Kepenghuluan Bakti Makmur Kecamatan Bagan Sinembah Kab. Rokan Hilir Riau," SISTEMASI, vol. 7, no. September, pp. 292-297, 2018.

[12] J. Simatupang, "Perancangan Sistem Inventori Barang pada Toko Nichos Jaya Menggunakan Metode FIFO," J. Intra Tech, vol. 1, no. 1, pp. 31-42, 2017.

[13] V. Sihombing, "Sistem Informasi Penjualan Mobil Suzuki Di Dealer Bagan Batu," SISTEMASI, vol. 7, no. 2, pp. 113-119, 2018.

[14] W. Purba, S. Tamba, and J. Saragih, "The effect of mining data k-means clustering toward students profile model drop out potential," J. Phys. Conf. Ser., vol. 1007, no. 1, p. 12049, 2018.

[15] A. Ardian, I. Purnama, and V. Sihombing, "Perancangan Aplikasi Pengolah Data Siswa Berbasis Android (Studi Kasus : Mis Nurul Huda Labuhan Batu Selatan)," Pengabdi. Masy. Ika Bina En Pabolo, vol. 1, no. 1, pp. 40-53, 2019. 
[16] Fricles Ariwisanto Sianturi, "Analisa metode teorema bayes dalam mendiagnosa keguguran pada ibu hamil berdasarkan jenis makanan," Tek. Inf. dan Komput., vol. 2, no. 1, pp. 87-92, 2019.

[17] V. M. M. Siregar, "Perancangan Sistem Informasi Inventaris Barang Pada Sekolah SMA Negeri 4 Pematangsiantar," IT J. Res. Dev., vol. 3, no. 1, pp. 54-61, 2018.

[18] V. M. M. Siregar, "Sistem Pendukung Keputusan Penentuan Insentif Bulanan Pegawai Dengan Menggunakan Metode Naïve Bayes," SISTEMASI, vol. 7, no. 2, pp. 87-94, 2018.

[19] H. A. Simbolon and V. M. M. Siregar, "Perancangan Sistem Informasi Berbasis E-Commerce Untuk Peningkatan Penjualan Produk Jersey Olah Raga," J. Tek. Inf. dan Komput., vol. 1, no. 2, pp. 49-54, 2018.

[20] V. M. Siregar and H. Sugara, "Perancangan Dan Implementasi Aplikasi Penggajian Berbasis Dekstop Pada Murni Sadar English Course," J. Tek. Inf. dan Komput., vol. 1, no. 2, pp. 42-48, 2018.

[21] V. M. M. Siregar, H. Sugara, and I. M. Siregar, "Perancangan Sistem Informasi Pendataan Barang Pada PT. Serdang Hulu," J. Comput. Bisnis, vol. 12, no. 2, pp. 111-117, 2018.

[22] S. S. S, A. T. Purba, and V. M. M. Siregar, "Sistem Penyeleksi Mahasiswa Baru Berbasis Web Menggunakan Metode Weighted Product," J. Tek. Inf. dan Komput., vol. 3, no. 1, p. 1, Sep. 2020.

[23] A. T. Purba and V. M. M. Siregar, "Sistem Penyeleksi Mahasiswa Baru Berbasis Web Menggunakan Metode Weighted Product," TEKINKOM, vol. 3, no. 1, pp. 1-8, 2020.

[24] A. T. Purba, "Sistem Pendukung Keputusan Dalam Penerimaan Mahasiswa Baru Dengan Metode Analytical Hierarchy Process (AHP)," $J$. Tekinkom, vol. 1, no. 1, pp. 1-7, 2018.

[25] S. Aisyah and W. Purba, "Aplikasi Sistem Pendukung Keputusan Penilaian Kinerja Karyawan Menggunakan Metode Profile Matching," J. Mahajana Inf., vol. 4, no. 2, pp. 16-20, 2019.

[26] S. P. Tamba, P. Wulandari, M. Hutabarat,
M. Christina, and A. Oktavia, "PENGGUNAAN METODE TOPSIS (TECHNIQUE FOR ORDER PREFERENCE BY SIMILARITY TO IDEAL SOLUTION) UNTUK MENENTUKAN KUALITAS BIJI KOPI TERBAIK BERBASIS ANDROID," J. Mantik Penusa, vol. 3, no. 1, pp. 73-81, 2019.

[27] Sahat Sonang, "Implementasi K-Means Dalam Evaluasi Kinerja Dosen Politeknik Bisnis Indonesia," $J$. Tekinkom, vol. 1, no. 1, pp. 32-40, 2018.

[28] J. Simatupang, "Sistem Pendukung Keputusan Penentuan Karyawan Terbaik Menggunakan Metode Saw Studi Kasus Amik Mahaputra Riau," J. Intra-Tech, vol. 2, no. 1, pp. 73-82, 2018.

[29] N. Aminudin, I. Ayu, and P. Sari, "Sistem Pendukung Keputusan (Dss) Penerima Bantuaprogram Keluarga Harapan (Pkh) Pada Desa Bangun Rejo Kec.Punduh Pidada Pesawaran Dengan Menggunakan Metode Analytical Hierarcy Process (Ahp)," J. TAM ( Technol. Accept. Model ), vol. 5, no. 2, pp. 66-72, 2015.

[30] D. S. Purnia, L. Lena, and R. Ratningsih, "Sistem Informasi Penentuan Calon PKH Menggunakan Metode SAW (Studi Kasus PPKH Kab.Tasikmalaya)," Indones. J. Softw. Eng., vol. 5, no. 2, pp. 135-148, 2019.

[31] Fadhliaziz and Sarjono, "Program Keluarga Harapan Dengan Simple Additive Weighting (Saw) Pada Dinas Sosial , Kependudukan Dan Pencatatan Sipil Provinsi Jambi," J. Manaj. Sist. Inf., vol. 4, no. 2, pp. 126-136, 2019.

[32] R. Hasanah, "Decision Support System Validation Recipient Program Keluarga Harapan ( PKH ) in Wonosari District using AHP- TOPSIS Method," vol. 5, no. 2, pp. 111-121, 2016.

[33] M. syawie, "Kemiskinan Dan Kesenjangan Sosial," Informasi, vol. 16, no. 03, pp. 213-219, 2011.

[34] M. Marbun and B. Sinaga, "Buku Ajar Sistem Pendukung Keputusan Penilaian Hasil Belajar Dengan Metode Topsis," Rudang Mayang Publ., no. Tahun, pp. 1-96, 2019. 